\title{
Reliability of quantification of Candida species colonies using alternative plating methods
}

\author{
Confiabilidade da quantificação de colônias de espécies de Candida utilizando métodos alternativos de \\ plaqueamento
}
Fiabilidad de la cuantificación de colonias de especies de Candida utilizando métodos alternativos de enchapado

Sarah Raquel de Annunzio¹, Filipe Silveira Fusco², Carolina Santezi², Bárbara Donadon Reina², Lívia Nordi Dovigo $^{2}$

\footnotetext{
${ }^{1}$ School of Pharmaceutical Sciences of São Paulo State University (UNESP), Department of Clinical Analysis. Araraquara, SP, Brazil.

${ }^{2}$ School of Dentistry of São Paulo State University (UNESP), Department of Social Dentistry. Araraquara, SP, Brazil.
}

\begin{abstract}
Objective: to evaluate the concordance of different plating methods for quantification of Candida species colonies. Method: standardized suspensions of reference strains (Candida albicans, Candida glabrata, Candida tropicalis and Candida krusei) were submitted to serial dilution and plating according to methods of track-dilution (TDM), drop plate (DPM) and the conventional spread plate (SPM). Data were submitted to construction of Bland-Altman diagrams, Intraclass Correlation Coefficient (ICC) and ANOVA ( $\alpha=5 \%$ ). Results: adequate concordance between the methods $(\mathrm{CCl}$ $>0.71)$ was observed, and the execution of DPM was the fastest $(p<0.001)$. However, DPM and TDM appear to result in greater values compared to SPM, especially for C. tropicalis and C. krusei. Conclusion: $C$. albicans and C. glabrata can be plated with DPM and TDM, but the use of these methods for C. krusei and C. tropicalis may result in count variation.
\end{abstract}

Descriptors: Candida albicans; Candida tropicalis; Candida glabrata; Data accuracy; Colony Count, Microbial.

\section{RESUMO}

Objetivo: avaliar a concordância de diferentes métodos de plaqueamento para a quantificação de colônias de espécies de Candida. Método: suspensões padronizadas das cepas de referência (Candida albicans, Candida glabrata, Candida tropicalis e Candida krusei) foram submetidas à diluição seriada e plaqueamento segundo os métodos plaqueamento em rastro (MPR), plaqueamento por gota (MPG) e o convencional espalhamento em placas (MEP). Os dados foram submetidos à construção de diagramas Bland-Altman, Coeficiente de Correlação Intraclasse (CCl) e ANOVA $(\alpha=5 \%)$. Resultados: foi observada adequada concordância entre os métodos $(\mathrm{CCl}>0,71)$, e a execução do MPG foi a mais rápida $(p<0,001)$. No entanto, o MPG e MPR parecem resultar em valores superiores em relação ao MEP, especialmente para $C$. tropicalis e $C$. krusei. Conclusão: $C$. albicans e $C$. glabrata podem ser plaqueadas com MPG e MPR, mas a utilização desses métodos para $C$. krusei e $C$. tropicalis podem resultar em variação na contagem.

Descritores: Candida albicans; Candida tropicalis; Candida glabrata; Confiabilidade dos Dados; Contagem de Colônia Microbiana.

\section{RESUMÉN}

Objetivo: evaluar la concordancia de diferentes métodos de recubrimiento para la cuantificación de colonias de especies de Candida. Método: las suspensiones estandarizadas de las cepas de referencia (Candida albicans, Candida glabrata, Candida tropicalis y Candida krusei) se sometieron a dilución en serie y recubrimiento de acuerdo con el recubrimiento de rastro (MRR), sembrado por gota (MSG) y los métodos de siembra convencionales (MEP). Los datos se sometieron a la construcción de diagramas de Bland-Altman, Coeficiente de Correlación Intraclase (CCI) y ANOVA $(\alpha=5 \%)$. Resultados: se observó un acuerdo adecuado entre los métodos ( $C C l>0,71)$, y la ejecución de la MSG fue la más rápida $(p<0,001)$. Sin embargo, MSG y MRR parecen dar lugar a valores más altos que MEP, especialmente para C. tropicalis y C. krusei. Conclusión: C. albicans y C. glabrata se pueden colocar en placas con MSG y MRR, pero el uso de estos métodos para $C$. krusei y $C$. tropicalis puede dar lugar a variaciones en el recuento.

Descriptores: Candida albicans; Candida tropicalis; Candida glabrata; Exactitud de los Datos; Recuento de Colonia Microbiana.

\section{How to cite:}

Annunzio SR, Fusco FS, Santezi C, Reina BD, Dovigo LN. Reliability of quantification of Candida species colonies using alternative plating methods. Rev Pre Infec e Saúde [Internet]. 2019;5:9426. Available from: http://www.ojs.ufpi.br/index.php/nupcis/article/view/9426 doi: https://doi.org/10.26694/repis.v5i0.9426

Rev Pre Infec e Saúde. 2019;5:9426 


\section{INTRODUCTION}

Genus Candida consists of heterogeneous fungal species, and some of them can act as opportunistic pathogens of humans. Candida albicans is considered the most prevalent species among infections, ${ }^{1}$ but other species such as Candida glabrata, Candida tropicalis and Candida krusei have often been isolated. ${ }^{2-4}$ The infections by Candida known as oral candidosis and oropharyngeal candidosis are considered the most frequent fungal pathologies among humans. ${ }^{1}$ Among immunocompromised individuals, the local infections may lead to systemic damage, in which the number of deaths as a result of infection by Candida spp. may vary between $40 \%$ to $80 \% \cdot{ }^{5-7}$

The search for new effective therapies in inactivation of Candida species and in reducing its ability to adhere to substrates such as dental prostheses, without causing collateral effects and/or antifungal resistance, is an important field of scientific investigations. ${ }^{8-9}$ In these studies, the growth and subsequent colony count in Petri plates has been a common practice in methodologies that seek to assess the effectiveness of new antimicrobial treatments. ${ }^{10}$

The conventional method used for enumeration of colony forming units per milliliter $(\mathrm{CFU} / \mathrm{mL})$ of Candida species is denominated spread plating (SPM). ${ }^{11}$ The enumeration by SPM begins with the sample serial dilution, followed by transferring aliquots of samples diluted to surface of a previously solidified agar and, with the help of a plastic, glass or steel spatula, the aliquot is uniformly distributed over the culture medium. ${ }^{12}$ After the incubation of plates for determined periods and temperature, the colonies are counted and, then, the cell concentration in original sample can be estimated referencing the volume of plate sample.

To increase the estimate precision of the number of $\mathrm{CFU} / \mathrm{mL}$ in samples, aliquots of each dilution are plated in duplicate or triplicate, and the colonies are counted only in plates referring to dilution that generated a number of colonies between 30 and $300 .{ }^{11,13}$ As the real concentration of microorganisms present in a sample after conclusion of an experiment is unknown, samples are often diluted up to seven times from the initial sample and only the replicates of a single dilution will be effectively used for count. ${ }^{13}$ Thus, this technique, although relatively accurate and widely used, has drawbacks such as the time spent to prepare materials and plating of samples, and the great amount of disposable plastics and culture media necessary for its proper performance. ${ }^{12,14}$

Alternative plating methods, in which it is possible to reduce material volume and time spent for its execution, have been proposed in literature, ${ }^{15-17}$ such as drop plating (DPM), ${ }^{11,13,18}$ spiral plating ${ }^{19}$ and track-dilution (TDM). ${ }^{12}$ The last one was initially proposed for the quantification of bacteria Enterococcus faecalis, Staphylococcus aureus, Bacillus subtilis and Escherichia coli plating in culture medium Brain Heart Infusion (BHI) and showed $\mathrm{CFU} / \mathrm{mL}$ values statistically similar to the conventional SPM for selected species. $^{12}$ TDM has significant advantages over SPM, such as its execution simplicity, shorter time required to prepare plates, plating and colony count and smaller volume of utilized material (plates and culture medium). That is probably why TDM has been 
Annunzio SR, et al.

widely used in applied microbiology studies, ${ }^{20-21}$ including in dentistry, ${ }^{22}$ and for quantification of yeast $^{23}$ and Candida species. ${ }^{9}$

Although TDM is widely used, reports that have previously verified its reliability and validity for plating and quantification of Candida species are not found. The measure accuracy question in laboratory studies is more relevant today than ever. Results obtained in a biased way, without previous assessment of precision and reliability of performed measures, may lead to incorrect results and release of erroneous information that, consequently, provoke the lack of reproducibility in science and even adoption of ineffective antimicrobial treatments in subsequent experiments. ${ }^{24}$

When different plating methods are used or when different researchers apply the same method, variations in microorganism count often occur. ${ }^{11}$ When neglected, such variations may negatively affect the study conclusions and make more difficult the comparison of results from different authors, especially those that seek to assess the effectiveness of antimicrobial therapies. Data published in literature already showed the importance of proposing standardized procedures and verifying reliability and reproducibility of plating method, in order to obtain reliable results, when it is about microbial quantification. However, such studies were conducted only for bacterial species. ${ }^{11,13}$

A previously published study ${ }^{25}$ already showed that obtaining high correlation between two plating methods was dependent on Candida species since they can differ in colony shape and size. The same authors also emphasized that the applicability of a new method for Candida
Quantification of Candida species colonies

enumeration depends on its ability to estimate $\mathrm{CFU} / \mathrm{mL}$ values from samples with high or low cell concentration. Moreover, the detection limit of each method should be considered. ${ }^{12}$ In this context, the objective of this study was to investigate TDM and DPM reliability for quantification of the number of $\mathrm{CFU} / \mathrm{mL}$ of different Candida species from samples with different cell concentrations and compare the time needed for execution of each method.

\section{METHOD}

\section{Experimental outline}

Experimental study performed in laboratory. The response variables investigated were $\mathrm{CFU} / \mathrm{mL}$ and procedure time (in minutes). As independent variables, the plating method (Spread plate method - SPM, Track-dilution method - TDM and Drop plate method - DPM) was considered.

\section{Strains and cultivation conditions}

Reference strains from company American Type Culture Collection (ATCC), from species Candida albicans (ATCC 90028), Candida glabrata (ATCC 2001), Candida tropicalis (ATCC 4563) and Candida krusei (ATCC 6258) were used. The microorganisms were kept under freezing (-70 degrees Celsius) until the moment of its usage in Yeast-Peptone-Glucose (Sigma Aldrich Co Ltd, Missouri, USA).

To obtain cell suspensions, experimental procedures of cell incubation, wash and resuspension were standardized. ${ }^{26}$ The cells were resuspended in $3 \mathrm{~mL}$ of phosphate-buffered saline (PBS) and 10-fold dilutions were performed. The samples were named D0 (initial suspension) to D5 (last dilution). Samples D0 to D5 were obtained in 
Annunzio SR, et al.

a standardized way on all occasions of the experiment, until they totaled 30 repetitions $(n=30)$.

\section{Sample plating}

Each sample was serially diluted in 96-well plates $^{27}$ (Kasvi, Paraná, Brazil) and aliquots of these dilutions were plated, in duplicate, in Petri plates containing Sabouraud Dextrose Agar medium with chloramphenicol (SDA; Acumedia Manufactures, Michigan, USA). The plating for later enumeration of the number of colonies was performed according to three different proposed methods: TDM, DPM and SPM.

For SPM, two $100 \mu \mathrm{L}$ aliquots of each dilution were individually transferred to two flatsurface round Petri plates $(90 \times 15 \mathrm{~mm}$; Kasvi, Paraná, Brazil) containing the previously solidified SDA medium. With the aid of a L-shaped sterile glass rod, the aliquots were evenly spread over the whole culture medium surface. For TDM, $10 \mu \mathrm{L}$ aliquots of serial dilutions were transferred, with the help of a multichannel pipette (Eppendorf, Hamburg, Germany) for two square Petri plates $(100 \times 15 \mathrm{~mm}, 13 \mathrm{~mm}$ grid; Simport Scientific, Canada) containing the previously solidified SDA medium. After transferring aliquots, the plates were inclined at an angle of approximately $45^{\circ}$ to the workbench surface, allowing that the aliquots formed tracks on the culture medium. In this method, it was possible to plate all samples (D0 to D5) in a same plate, and a second plate was used for the duplicates. When the track formed by any of the aliquots reached the distance of $5 \mathrm{~mm}$ from agar edge, the plate was slightly tilted back to avoid aggregation of tracks at the plate base. For DPM, $10 \mu \mathrm{L}$ aliquots

\section{Quantification of Candida species colonies}

in duplicate from serial dilutions were transferred, with the aid of a multichannel pipette, to Petri plates containing the previously solidified SDA medium.

For all the methods, the plates were let on the workbench for 10 minutes and then, inverted and incubated at $37^{\circ} \mathrm{C}$. For SPM, the incubation time used was $48 \mathrm{~h}$, which enables the colony growth in proper size to avoid their joining. Nevertheless, in TDM and DPM, the colony growth area was much smaller and thus, the incubation time of $20 \mathrm{~h}$ and $18 \mathrm{~h}$ was defined, respectively.

After the incubation period, all the plates were photographed on a black background, in a standardized way, and the colony count was performed in photographs, with the help of the Count tool in Adobe Photoshop (Adobe Systems Incorporated, San Jose, CA, USA) software, by two previously and properly calibrated researchers $(\mathrm{CCl}=0.995)$. For SPM, the plating volume was $0.1 \mathrm{~mL}$, and the count was performed in the dilution that presented growth between 30 and 300 colonies, considering the count pattern in literature. As in TDM and in DPM, the plating volume was $0.01 \mathrm{~mL}$, the growth pattern does not enable number of countable colonies above 30 colonies. Therefore, the count was performed in dilution that presented between 3-30 colonies because the plating volume in these methods was 10 times smaller than the plating volume in SPM. The time (in minutes) needed for plating (excluding the procedure of serial dilution) and colony count was measured with the aid of a digital stopwatch (Kasvi, Paraná, Brazil), by an independent researcher. 
Annunzio SR, et al.

\section{Data analysis}

The values of $\mathrm{CFU} / \mathrm{mL}$ were transformed in $\log _{10}$. The reproducibility between the methods was estimated through Intraclass Correlation Coefficient (ICC) and its Confidence Interval $\left(\mathrm{Cl}_{95 \%}\right)$, considering the absolute concordance and the two-way mixed effect model analysis of variance, for average measurements. ${ }^{28}$ Depending on the ICC value obtained, the concordance rate between the measures was classified according to Fermanian proposal. ${ }^{29}$ The effect of the plating type over the $\log _{10}(\mathrm{CFU} / \mathrm{mL})$ variable was also analyzed through repeated measures analysis of variance. The analysis of plating procedure times and count used one-way analysis of variance with Welch correction, followed by Games-Howell post-hoc test. The null hypothesis of this study was that there is no effect from different plating methods and from different species in number of colonies recovered after plating and in method
Quantification of Candida species colonies

execution time. Significance level was set at $5 \%$ in all analyses, which are performed in IBM Statistical Package for the Social Sciences (SPSS) Statistics 21 software.

\section{RESULTS}

In this study, the three plating methods were compared regarding their concordance to obtain $\mathrm{CFU} / \mathrm{mL}$ values (Figure 1). Descriptive data analysis pointed out that, in a general way, both alternative methods (Track-dilution method TDM and Drop plate method - DPM) seemed to result, systematically, in $\log _{10}(\mathrm{CFU} / \mathrm{mL})$ values slightly higher in relation to traditional method (Spread plate method - SPM) (Table 1). BlandAltman ${ }^{30}$ diagrams (Figure 2) corroborated this behavior, especially for Candida tropicalis and Candida krusei species since most of the differences between $\log _{10}(\mathrm{CFU} / \mathrm{mL})$ values (SPM TDM and SPM - DPM) were negative. 
Figure 1: Petri plates images containing Candida colonies.

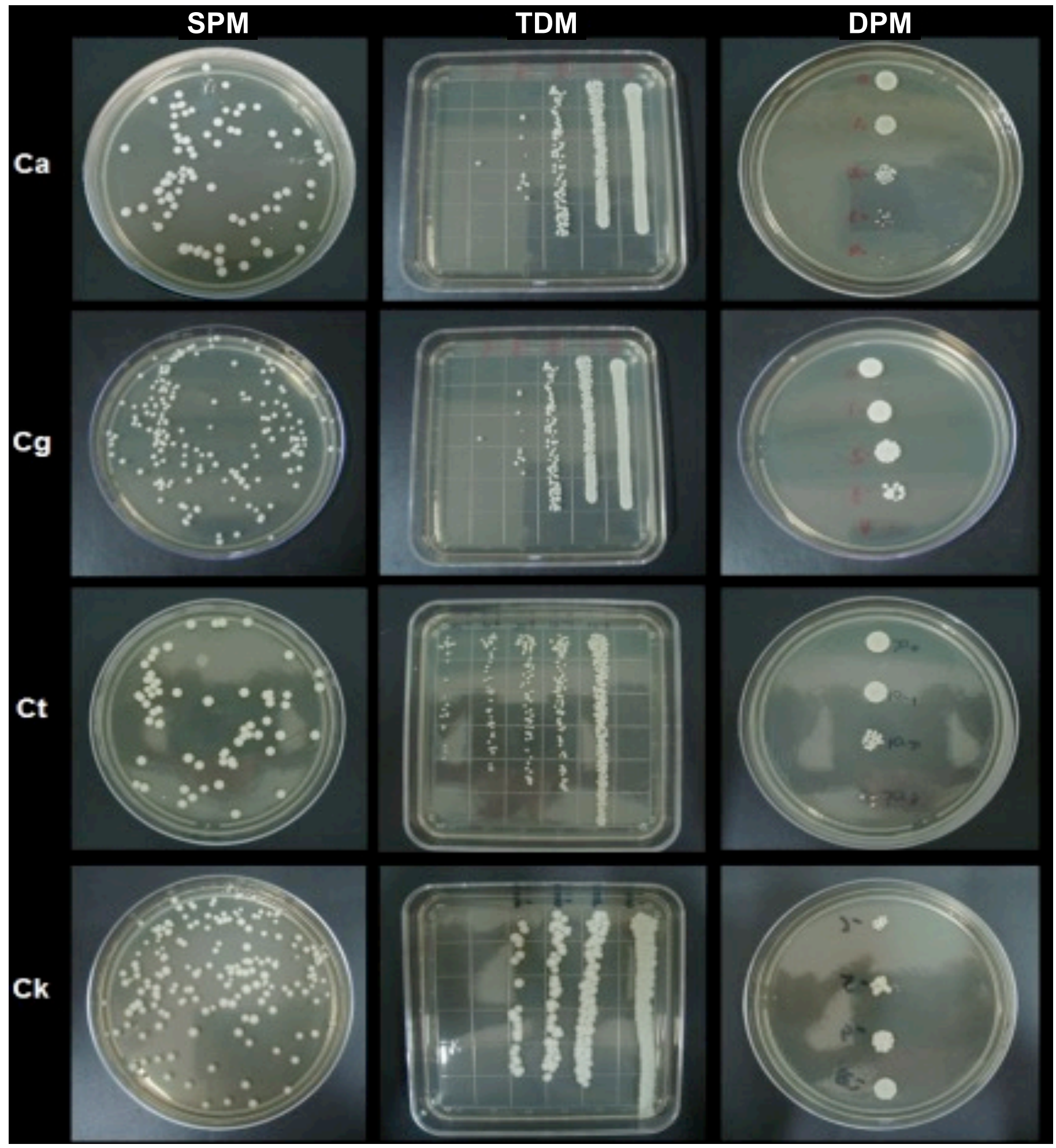

Caption: SPM: Spread plate method; TDM: Track-dilution method; DPM: Drop plate method; Ca: Candida albicans; Cg: Candida glabrata; Ct: Candida tropicalis; Ck: Candida krusei. 
Figure 2: Bland-Altman diagrams for concordance descriptive analysis between the plating methods according to Candida species.
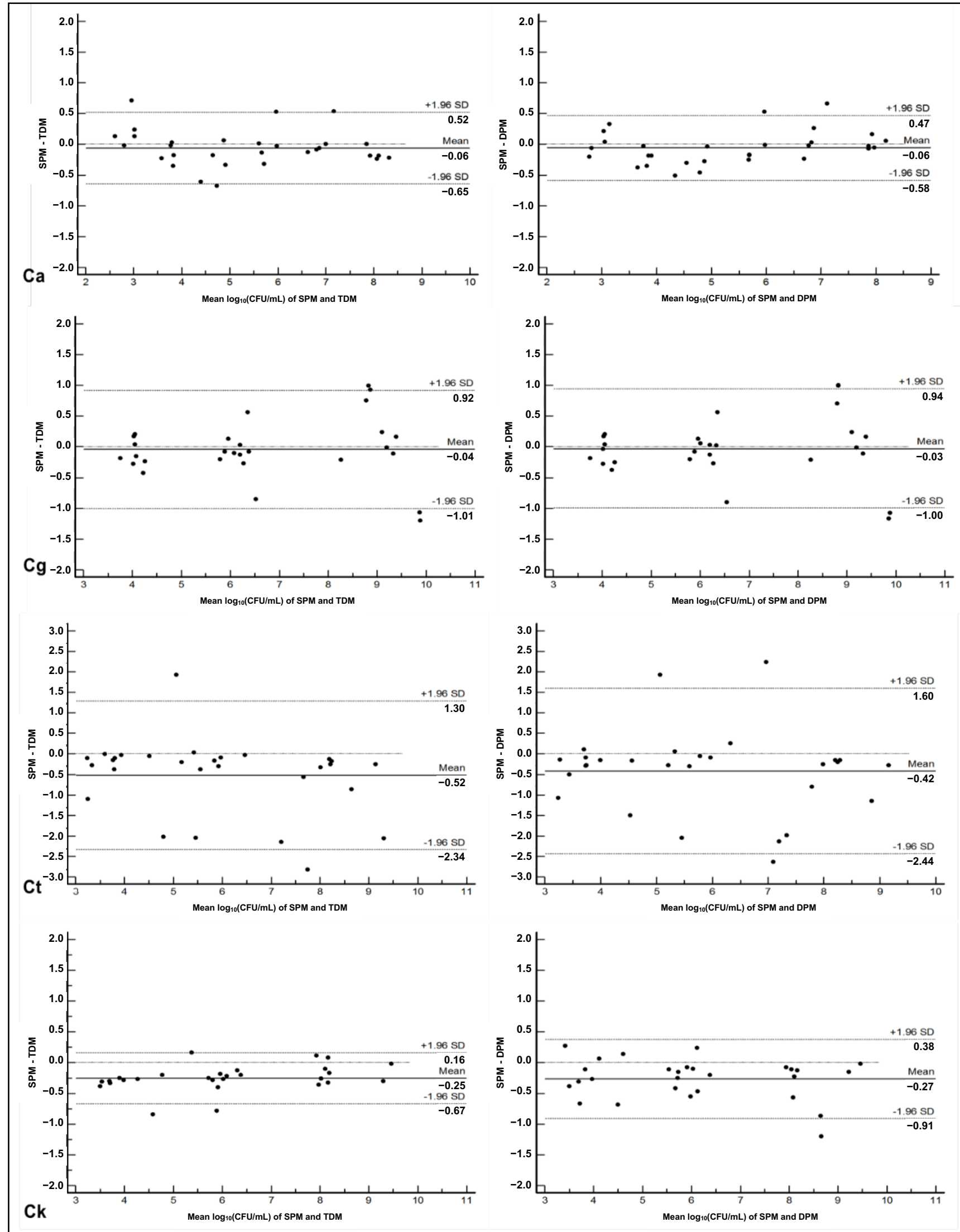

Caption: SPM: Spread plate method; TDM: Track-dilution method; DPM: Drop plate method; $x$ axis: value mean of each method with the SPM values; y axis: difference between each method and SPM. 
Annunzio SR, et al.

The difference between means was also investigated and considered statistically significant for $C$. krusei species. Bonferroni posttest pointed out smaller values in SPM compared to TDM and DPM $(p \leq 0.001)$, and the last ones were
Quantification of Candida species colonies considered similar to each other $(p=1.000)$. Nevertheless, the reproducibility analysis pointed out an adequate concordance between methods because all ICC values were above the value of 0.71 (Table 2).

Table 1: $\log _{10}(\mathrm{CFU} / \mathrm{mL}$ ) mean values (and standard deviation) obtained after plating colonies of four Candida species using different plating methods.

\begin{tabular}{lccccccc}
\hline Species & SPM & \multicolumn{3}{c}{ TDM } & \multicolumn{1}{c}{ DPM } & $\mathrm{p}^{*}$ \\
\hline Candida albicans & 5.32 & $(1.80)$ & 5.38 & $(1.81)$ & 5.38 & $(1.70)$ & 0.333 \\
Candida glabrata & 6.61 & $(2.12)$ & 6.64 & $(2.11)$ & 6.63 & $(2.11)$ & 0.696 \\
Candida krusei & 5.97 & $(1.85)$ & 6.23 & $(1.80)$ & 6.24 & $(1.91)$ & $<0.001$ \\
Candida tropicalis & 5.71 & $(1.90)$ & 6.17 & $(2.10)$ & 6.07 & $(1.97)$ & 0.079 \\
\hline
\end{tabular}

Caption: *p-values obtained from repeated measures analysis of variance. SPM: Spread plate method; TDM: Track-dilution method; DPM: Drop plate method.

Table 2: Intraclass Correlation Coefficient values and respective 95\% Confidence Interval for reproducibility analysis between the three different plating methods according to Candida species.

\begin{tabular}{lllll}
\hline Species & ICC & $\mathrm{Cl}_{95 \%}$ & & \\
\hline Candida albicans & 0.997 & 0.994 & $\mathrm{H}$ & 0.998 \\
Candida glabrata & 0.994 & 0.989 & $\mathrm{H}$ & 0.997 \\
Candida krusei & 0.993 & 0.983 & $\mathrm{H}$ & 0.997 \\
Candida tropicalis & 0.946 & 0.899 & $\mathrm{H}$ & 0.973 \\
\hline
\end{tabular}

Caption: ICC: Intraclass Correlation Coefficient; $\mathrm{Cl}_{95 \%}$ : 95\% Confidence Interval.

The results also showed that the two alternative methods were able to slightly shorten the worktime compared to the traditional method, concerning both plating and colony count (Figure 3). 
Figure 3: Time mean (minutes), and standard deviation, for plating execution (A) and colony count (B) of Candida samples according to used method. Differences between means were considered statistically significant according to Welch's ANOVA (A: $F=613,410 ; p<0.001 / B$ : $F=422,614$; $p<0.001)$. Different letters denote different means according to Games-Howell test $(p<0.001)$.
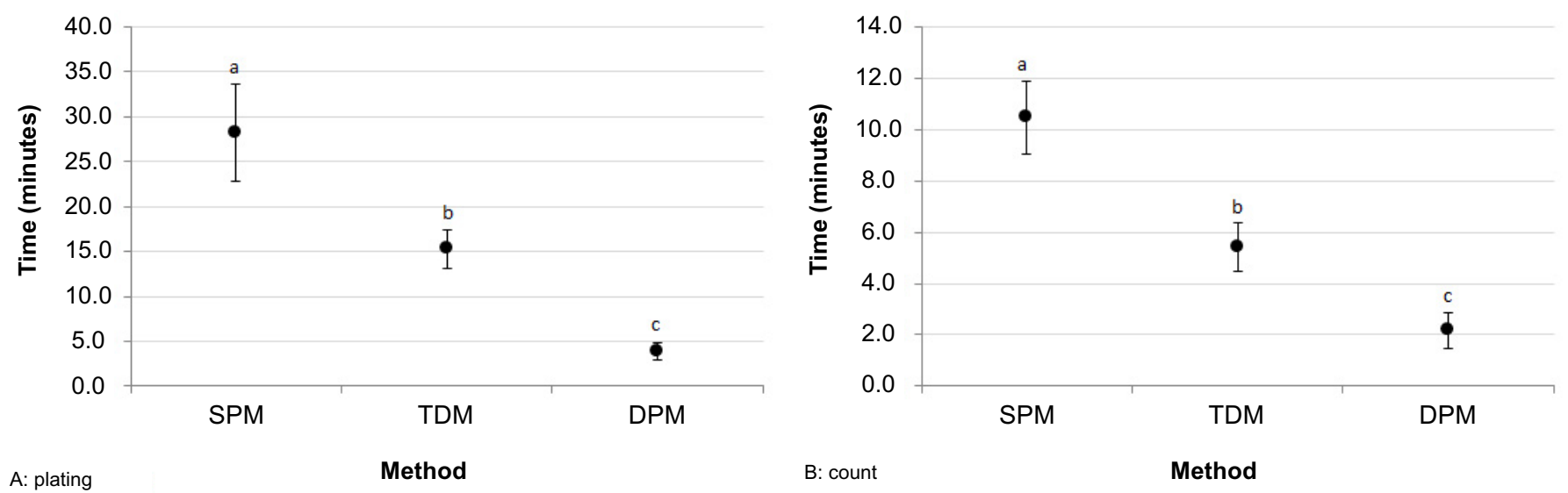

\section{DISCUSSION}

Infections caused by Candida species are normally associated with biofilm formation by fungal species and are difficult to treat. ${ }^{1}$ For this reason, studies have tried to comprehend the genetic and biochemical aspects of biofilm development and drug resistance as well as knowing the prevalence in vulnerable groups and establish new antimicrobial strategies. ${ }^{31-32}$ In all these study types, it is fundamentally important to quantify in an accurate and reproductible way the number of viable cells in studied samples.

The estimate of the number of viable microorganisms in microbiological samples was described more than one hundred years ago and even today can be considered one of the pillars of microbiology. This quantification is typically performed by counting the total number of colony forming units (CFU) growth on a agar plate from serial dilutions. The conventional method used for CFU enumeration of Candida species is denominated spread plating (SPM). ${ }^{11}$ However, SPM has drawbacks as the time spent for its execution and the large volume of necessary

material. ${ }^{12,14}$ Thus, alternative plating methods have been proposed in literature.

Referring to concordance between the evaluated methods in this study, it was observed that both alternative methods (Track-dilution method - TDM and Drop plate method - DPM) resulted, systematically, in $\log _{10}(\mathrm{CFU} / \mathrm{mL})$ values slightly higher in relation to traditional method (SPM). It has already been reported that SPM may underestimate $\mathrm{CFU} / \mathrm{mL}$ values compared to alternative plating methods. ${ }^{11}$ The usage of glass or plastic handle, necessary for sample spreading in SPM, may provoke injury to microbial cells and affect the number of CFU depending on spreading time and execution way, which could explain the current study results.

The difference between the means was considered statistically significant only for Candida krusei species, since the alternative methods were considered similar to each other. Thus, although the observed SPM tendency to underestimate the $\log _{10}(\mathrm{CFU} / \mathrm{mL})$ value, it seemed that this problem was in fact evidenced only for $C$. krusei species. The study leaded by 
Annunzio SR, et al.

Walsh and colaborators ${ }^{25}$ also showed the occurrence of weaker correlation between SPM and spiral technique for C. krusei, compared to results obtained with Candida albicans and Candida glabrata. C. krusei colony shape is different from other assessed species, they have a more widespread growth with rough texture and may require a shorter incubation time in order to avoid colony overlap and consequently count error. It was already suggested that, in single species cultures, the incubation time and dilution selected for count may depend on size of formed cells and colonies. ${ }^{11}$ As the hypothesis of cell damage due to handle used in SPM was not assessed in Candida species, it cannot be said if SPM underestimated the colonies or, conversely, TDM and DPM overestimated the estimate. Although significant, C. krusei count difference observed in this study between SPM and other methods did not exceed, on average, 0.3 log, which may be a difference without practical importance, depending on required accuracy in different studies that come to use alternative methods. Thus, the $C$. krusei species plating with DPM and TDM should still be viewed with caution and could be investigated in the future using other strains such as, for example, clinical isolates.

Even so, the reproducibility analysis pointed out an adequate concordance between methods since all ICC values were above the value of 0.71 , considered limit for a good concordance. Candida tropicalis was the species that presented the lowest ICC value and the most inaccurate $\mathrm{Cl}_{95 \%}$. This result has already been suggested by Bland-Altman plot, ${ }^{30}$ in which it is possible to verify greater dispersion of differences in

\section{Quantification of Candida species colonies}

$\log _{10}(\mathrm{CFU} / \mathrm{mL})$ values between methods; some samples presented differences greater than 2 log. This result shows the importance of using more than one statistical method in analysis to conclude about the reliability between methods. Although ANOVA has not identified the differences in means for this species, the decision was close to the significance threshold which also draws attention to greater caution using alternative methods for this species.

The current study also sought to perform a comparison of procedure time of DPM, TDM and SPM methods for quantification of Candida species. The two alternative methods were able to slightly shorten the worktime compared to the traditional method. Shortening the time to perform plating was already expected because both methods (DPM and TDM) have very simplified stages in relation to SPM, and TDM procedure length in bacterial species has already been documented. ${ }^{12}$ As regards the colony count, the most likely explanation for time reduction is related to the lower number of CFU obtained through alternative methods. Both in TDM and in DPM, the plating volume is 10 times smaller than SPM one, and, then, a smaller number of colonies is expected. For this reason, studies that use DPM indicate the colony count in dilution that presents between 3-30 colonies, ${ }^{13}$ opposing to standard recommendation that is between $30-300$ colonies. ${ }^{13,18}$ Our results showed that the DPM execution, both colony plating and count, was faster than TDM and significantly faster than SPM. This result is directly related with the procedure of that method since it enables the use of multichannel pipette and plating of at least six aliquots in the same plate. Moreover, it was 
already reported that the higher microorganism concentration in the sample, the greater the difference in time for colony count between DPM and SPM. ${ }^{13}$ It is worth noting that, although the smaller volume and, consequently, lower number of formed colonies, the CFU value considered is always relative to the plating volume (CFU/mL or CFU/mg) without, in theory, discrepancies justified by these differences between TDM and DPM methods with SPM.

As main limitations of this study, the following is considered: the use of only one strain per species and the use of only one culture medium type for fungal species. Therefore, future studies could broaden the knowledge on this subject, investigating those other variables.

\section{CONCLUSION}

This study evidences, considering its limitations, make it possible to conclude that the null hypothesis that there is no effect from different plating methods in number of colonies recovered after plating can only be accepted for Candida albicans, Candida glabrata and Candida tropicalis species. Thus, these species can be plated through track-dilution method (TDM) and drop plate method (DPM) without damaging the quality of obtained data. Nevertheless, for Candida krusei species, some variations in colony count compared to spread plate method may be expected, and, then, the use of alternative methods should be done with caution depending on required objective and accuracy in each study. If the objective is not based on estimation of frequencies and prevalence in a certain population, and only on comparing the number of colonies between study groups instead, it is believed that the methods can be applied without damaging information. Relating to the execution time, the null hypothesis that there is no effect from different plating methods in method execution time was rejected. DPM and TDM considerably shortened the plating execution time and colony count of Candida species, and DPM is the one that requires the shortest time among the three methods.

\section{REFERENCES}

1. Millsop JW, Fazel N. Oral candidiasis. Clin Dermatol [Internet]. 2016 Jul [cited 2019 Dec 16]; 34(4):487-94. Available from: http://dx.doi.10.1016/j.clindermatol.2016.02.0 22

2. Kalantar E, Marashi SM, Pormazaheri $\mathrm{H}$, Mahmoudi E, Hatami S, Barari MA, et al. First experience of Candida non-albicans isolates with high antibiotic resistance pattern caused oropharyngeal candidiasis among cancer patients. J Cancer Res Ther [Internet]. 2015 Apr [cited 2019 Dec 16]; 11(2):388-90. Available from: http://dx.doi.0.4103/0973-1482.157307

3. Cortegiani A, Misseri G, Chowdhary A. What's new on emerging resistant Candida species.Intensive Care Med [Internet]. 2019 Apr [cited 2019 Dec 16]; 45(4):512-515. Available from: http://dx.doi.org/10.1007/s00134-0185363-x

4. Taei M, Chadeganipour M, Mohammadi R. An alarming rise of non-albicans Candida species and uncommon yeasts in the clinical samples; a combination of various molecular techniques for identifcation of etiologic agents. BMC Res Notes [Internet]. 2019 Nov [cited 2019 Dec 16]; 12:779$89 . \quad$ Available from: http: / /dx.doi.org/10.1186/s13104-019-4811-1

5. Brunetti G, Navazio AS, Giuliani A, Giordano A, Proli EM, Antonelli G, et al. Candida blood stream infections observed between 2011 and 2016 in a large Italian University Hospital: A time-based retrospective analysis on epidemiology, biofilm production, antifungal agents consumption and drug-susceptibility. Plos one [Internet]. 2019 Nov 
[cited 2019 Dec 16]; 4(11):1-10. Available from: http://dx.doi.org/10.1371/journal.pone.022467 8

6. Antinori S, Milazzo L, Sollima S, Galli M, Corbellino M. Candidemia and invasive candidiasis in adults: A narrative review.Eur J Intern Med [Internet]. 2016 Oct [cited 2019 Dec 16]; 34:2128. Available from: http://dx.doi.org/10.1016/j.ejim.2016.06.029

7. Fernández-Ruiz $M$, Puig-Asensio $M$, Guinea J, Almirante B, Padilla B, Almela $M$, et al. Candida tropicalis bloodstream infection: Incidence, risk factors and outcome in a population-based surveillance. J Infect [Internet]. 2015 Sep [cited 2019 Dec 16]; 71(3):385-94. Available from: http://dx.doi.org/10.1016/j.jinf.2015.05.009

8. Carmello JC, Dovigo LN, Mima EG, Jorge JH, de Souza Costa CA, Bagnato VS, et al. In vivo evaluation of photodynamic inactivation using Photodithazine $^{\circledR}$ against Candida albicans. Photochem Photobiol Sci [Internet]. 2015 Jul [cited 2019 Dec 16]; 14(7):1319-28. Available from: http://dx.doi.org10.1039/c4pp00368c

9. Dovigo LN, Carmello JC, de Souza Costa CA, Vergani CE, Brunetti IL, Bagnato VS, et al. Curcumin-mediated photodynamic inactivation of Candida albicans in a murine model of oral candidiasis. Med Mycol [Internet]. 2013 Apr [cited 2019 Dec 16]; 51(3):243-51. Available from: http://dx.doi.10.3109/13693786.2012.714081

10. Taff HT, Nett JE, Andes DR. Comparative analysis of Candida biofilm quantitation assays. Med Mycol [Internet]. 2012 Apr [cited 2019 Dec 16]; 50(2):214-8. Available from: http://dx.doi.10.3109/13693786.2011.580016

11. Thomas P, Sekhar AC, Mujawar MM. Nonrecovery of varying proportions of viable bacteria during spread plating governed by the extent of spreader usage and proposal for an alternate spotting-spreading approach to maximize the CFU. J Appl Microbiol [Internet]. 2012 Aug [cited 2019 Aug 30]; 113(2):339-50. Available from: https://doi.org/10.1111/j.13652672.2012.05327.x

12. Jett BD, Hatter KL, Huycke MM, Gilmore MS. Simplified agar plate method for quantifying viable bacteria. Biotechniques [Internet]. 1997 Oct [cited 2019 Aug 30]; 23(4):648-50. Available from: https://doi.org/10.2144/97234bm22

13. Herigstad $B$, Hamilton M, Heersink J. How to optimize the drop plate method for enumerating bacteria. J Microbiol Methods [Internet]. 2001 Mar [cited 2019 Aug 30]; 44(2):121-29. Available from: https://doi.org/10.1016/S0167-7012(00)00241-4 14. Sieuwerts S, De Bok FA, Mols E, De Vos WM, Vlieg JE. A simple and fast method for

Rev Pre Infec e Saúde. 2019;5:9426 determining colony forming units. Lett Appl Microbiol [Internet]. 2008 Oct [cited 2019 Aug 30]; 47(4):275-8. Available from: http://dx.doi.10.1111/j.1472-765X.2008.02417.x 15. Hamilton CM, Anderson M, Lape J, Creech E, Woessner J. Multichannel plating unit for highthroughput plating of cell cultures. Biotechniques [Internet]. 2002 Sep [cited 2019 Aug 30]; 33(2):420-3. Available from: https: / / doi.org/10.2144/02332ht02

16. McNulty JJ, Dunn JJ. High-throughput transformation and plating using petristrips. Biotechniques [Internet]. 1999 Aug [cited 2019 Aug 30]; 26(3):390-2. Available from: https: //doi.org/10.2144/99263bm04

17. Tornero P, Dangl JL. A high-throughput method for quantifying growth of phytopathogenic bacteria in Arabidopsis thaliana. Plant J [Internet]. 2002 Jan [cited 2019 Aug 30]; 28(4):475-81. Available from: https: //doi.org/10.1046/j.1365-

313X.2001.01136.x

18. Barbosa HR, Rodrigues MF, Campos CC, Chaves ME, Nunes I, Juliano Y, et al. Counting of viable cluster-forming and non cluster-forming bacteria: A comparison between the drop and the spread methods. J Microbiol Methods [Internet]. 1995 Apr [cited 2019 Aug 30]; 22(1):39-50. Available from: https://doi.org/10.1016/01677012(94)00062-C

19. Robinson SE, Wright EJ, Williams NJ, Hart CA, French NP. Development and application of a spiral plating method for the enumeration of Escherichia coli 0157 in bovine faeces. J Appl Microbiol [Internet]. 2004 Jun [cited 2019 Aug 30]; 97(3):581-9. Available from: https://doi.org/10.1111/j.1365-

2672.2004.02339.x

20. Dai T, Garcia B, Murray CK, Vrahas MS, Hamblin MR. UVC light prophylaxis for cutaneous wound infections in mice. Antimicrob Agents Chemother [Internet]. 2012 Jul [cited 2019 Aug 30]; 56(7):3841-8. Available from: https://aac.asm.org/content/aac/56/7/3841.ful l.pdf

21. Stamps JA, Yang LH, Morales VM, Boundy-Mills KL. Drosophila Regulate yeast density and increase yeast community similarity in a natural substrate. PLoS One [Internet]. 2012 Jul [cited 2019 Aug 30]; 7(7):1-12. Available from: https://doi.org/10.1371/journal.pone.0042238

22. Garcez AS, Nuñez SC, Hamblin MR, Ribeiro MS. Antimicrobial effects of photodynamic therapy on patients with necrotic pulps and periapical lesion. J Endod [Internet]. 2008 Feb [cited 2019 Aug 30]; 
$34(2): 138-42$.

Available

from:

https://doi.org/10.1016/j.joen.2007.10.020

23. Kato IT, Prates RA, Sabino CP, Fuchs BB, Tegos

GP, Mylonakis E, et al. Antimicrobial photodynamic inactivation inhibits Candida albicans virulence factors and reduces in vivo pathogenicity. Antimicrob Agents Chemother [Internet]. 2013 Jan [cited 2019 Aug 30]; 57(1):445-51. Available from: https://www.ncbi.nlm.nih.gov/pmc/articles/PM C3535901/pdf/zac445.pdf

24. Viljoen A, Twomey PJ. True or not: uncertainty of laboratory results. J Clin Pathol [Internet]. 2007 Jun [cited 2019 Aug 30]; 60(6):587-8. Available from: http://dx.doi.org/10.1136/jcp.2006.042333

25. Walsh TJ, Venanzi WE, Dixon DM. Quantification of medically important Candida species and Torulopsis glabrata by a spiral inoculation system: correlation with pour plate and spread plate methods. J Clin Microbiol [Internet]. 1985 Nov [cited 2019 Aug 30]; 22(5):745-7. Available from: https://www.ncbi.nlm.nih.gov/pmc/articles/PM C268518/pdf/jcm00112-0081.pdf

26. Dovigo LN, Pavarina AC, Ribeiro AP, Brunetti IL, Costa CA, Jacomassi DP, et al. Investigation of the photodynamic effects of curcumin against Candida albicans. Photochem Photobiol [Internet]. 2011 Apr [cited 2019 Aug 30]; 87(4):895-903. Available from: https://doi.org/10.1111/j.1751-

1097.2011.00937.x

27. Chen CY, Nace GW, Irwin PL. A $6 \times 6$ drop plate method for simultaneous colony counting and MPN enumeration of Campylobacter jejuni,
Listeria monocytogenes, and Escherichia coli. J Microbiol Methods [Internet]. 2003 Nov [cited 2019 Aug 30]; 55(2):475-9. Available from: https://doi.org/10.1016/s0167-7012(03)00194-5

28. McGraw KO, Wong SP. Forming inferences about some intraclass correlations coefficients. Psychol Methods [Internet]. 1996 Jan [cited 2019 Aug 30]; 1(1):30-46. Available from: https: / / doi.org/10.1037/1082-989X.1.4.390

29. Fermanian J. Mesure de l'accord entre deux juges. Cas qualitatif. Rev Epidemiol Sante Publique [Impresso]. 1984 [cited 2019 Aug 30]; 32(2):140-7.

30. Bland JM, Altman DG. Measuring agreement in method comparison studies. Stat Methods Med Res [Internet]. 1999 Apr [cited 2019 Aug 30]; 8(2):135-160. Available from: https: / /doi.org/10.1177/096228029900800204 31. Telles DR, Karki N, Marshall MW. Oral Fungal Infections. Dent Clin North Am [Internet]. 2017 Apr [cited 2019 Aug 30]; 61(2):319-349. Available from:

https: / / doi.org/10.1016/j.cden.2016.12.004 32. Paulone S, Malavasi G, Ardizzoni A, Orsi CF, Peppoloni S, Neglia RG, et al. Candida albicans survival, growth and biofilm formation are differently affected by mouthwashes: an in vitro study. New Microbiol [Internet]. 2017 Jan [cited 2019 Dec 16]; 40(1):45-52. Available from: http://www.newmicrobiologica.org/PUB/allegat i_pdf/2017/1/45.pdf

Submitted: 2019-11-03

Accept: 2019-12-15

Published: 2019-12-31

\section{COLLABORATIONS}

SRA, FSF, CS and BDR: substantial contributions in data collecting, analysis and interpretation, and in article writing. LND: substantial contributions in work conception or design; data analysis and interpretation, and in article writing. All the authors agree and are responsible for the content of this manuscript version to be published.

\section{ACKNOWLEDGMENTS}

Does not apply.

\section{AVAILABILITY OF DATA}

Does not apply.

FUDING SOURCE

FAPESP 2013/03863-0 and 2013/04153-6. 


\section{CONFLICTS OF INTEREST}

There are no conflicts of interest to declare.

\section{CORRESPONDENCE}

Lívia Nordi Dovigo

Address: Rua Humaitá, 1680, CEP:14801-903, Araraquara, SP, Brazil

Telephone: +55 (16) 33016552

E-mail: livia.dovigo@unesp.br 